\title{
Mean Platelet Volume and Aggregation in Children with Ulcerative Colitis
}

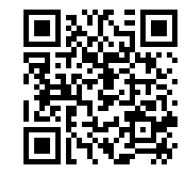

\author{
G Ya Levin*, AN Popovicheva, LN Sosnina, OV Fedorova and Yu A Sheremet'ev \\ Federal State Budgetary Educational Institution of Higher Education, Research Medical University of the Ministry of Health of the Russian Federation, Russia
} Received: April 21, 2018; Published: May 08, 2018

*Corresponding author: G Ya Levin, Federal State Budgetary Educational Institution of Higher Education Privolzhsky, Research Medical University of the Ministry of Health of the Russian Federation, Russia

Abbreviations: Mean Volume; IBD: Inflammatory Bowel Disease; UC: Ulcerative Colitis; MVs: Microvesicles; PUCAI: Pediatric Ulcerative Colitis Activity Index; TNF: Infliximab and Adalimumab

\section{Introduction}

Several studies suggested that platelets might play a crucial role in pathogenesis of inflammatory bowel disease (IBD) [1,2]. There is solid evidence demonstrating that platelets, in addition to their traditional role in hemostasis, can also function as potent proinflammatory cells [3]. Upon activation, platelets secrete a large number of biologically active molecules able to activate an inflammatory process. At the same time, the morphology of platelets changes and their mean volume (MPV) reduces [4]. Low MPV can be a marker of activity of IBD [5]. However, the way the functional properties of platelets change, primarily their aggregation capacity, remains unclear. Small platelets have lower functional abilities and larger platelets are metabolically and enzymatically more active $[6,7]$. Therefore, an important objective of this research was to study spontaneous platelet aggregation and evaluate the correlation of aggregation and platelet size (MPV) at IBD, specifically, in Ulcerative Colitis (UC).It should be noted that most of the studies that discuss the problem of the relationship between the platelet size and the severity of IBD are performed in adult patients. There have been no similar studies in pediatric patients.

\section{Materials and methods}

All patients and healthy donors agreed to participate in the study and signed informed consent forms of FSBEI HE PRMU MOH Russia. The permission of the local ethical committee was obtained for the study. The informed consent was obtained from parents of all children (or from children older than 15 years) for participation in the study. The study included 30 patients of both sexes ages 6 to 17 with UC. The diagnosis was based on a complex examination including clinical and laboratory data, as well as endoscopic examination of the intestinal mucosa with a morphological analysis of biopsies. The activity of the disease was evaluated according to the pediatric index of PUCAI (Pediatric Ulcerative Colitis Activity Index).

The treatment was performed with the use of derivatives of 5-aminosalicylic acid, gluco-corticosteroids, immune suppressive drugs, antibodies to TNF (infliximab and adalimumab). The results of the research were compared to the corresponding indexes of 30 conditionally healthy children of both sexes and same age as the control group. Spontaneous (shear-induced) aggregation of erythrocytes was studied using a rheoscope designed according to the method [8] in our modification [9] with video recording of the process of aggregation and its digital microphotoshooting. The micropictures were treated on a computer with a specially developed program. The results of the study were processed with methods of non-parametric statistics using Mann-Whitney test and Wilcoxon matched pairs test. The correlation analysis (Spearman's method) was used to study the relationships between the parameters. Differences were considered statistically significant at $\mathrm{p}<0.05$.

\section{Results}

Results show that the mean platelet volume and the platelet distribution width (PDW) significantly decrease at UC: MPV from $8.59 \pm 0.08$ to $7.75 \pm 0.14(\mathrm{p}<0.05)$, PDW - from $14.72 \pm 0.28$ to $12.03 \pm 0.45(\mathrm{p}<0.05)$. During the treatment platelet indices (MPV and PDW) in patients with UC increase and achieve the norm.A study of the aggregation function of platelets in UC was performed. It was established that the rate of spontaneous platelet aggregation increased significantly in UC (the time of beginning aggregation was shortened from $116.00 \pm 8.33 \mathrm{~s}$ to $86.00 \pm 8.98 \mathrm{~s}, \mathrm{p}<0,05)$. The number of aggregates increases and their formation accelerates (the time of appearance of large aggregates was shortened from 224.00 
$\pm 17.71 \mathrm{~s}$ to $170.00 \pm 14.99 \mathrm{~s}, \mathrm{p}<0.05$ ). In the process of treatment spontaneous aggregation of platelets decreases and achieves the norm. Correlation analysis revealed a negative correlation between MPV and the rate of platelet aggregation in patients with UC ( $\mathrm{r}=$ $-0.50, \mathrm{p}<0.05$ ).

\section{Conclusion}

It has been established that, with a reduced volume, platelets not only retain high aggregation activity, but it even intensifies. There is a negative correlation between MPV and the degree of platelet aggregation in UC. One of the reasons for increasing platelet aggregation in IBD can be thrombinemia [10]. The reasons of the reduction of MPV in IBD remain unclear. Reduction of MPV in UC may be associated with impaired thrombocytopoiesis, often observed in systemic inflammatory processes [11]. We believe that a decrease in MPV in IBD may be due to increased microvesiculation of blood cells, which occurs with IBD [12]. According to the literature data, a large number of microvesicles (MVs) in the blood have a platelet origin. The release of MVs is not only accompanied by a decrease in MPV. MVs themselves play an important role in the pathogenesis of various diseases, especially those accompanied by a risk of thrombotic complications [13] and can initiate inflammation.

\section{References}

1. Albayrak Y, Albayrak A, Albayrak F, Yildirim R, Aylu B, et al. (2011) Mean platelet volume: a new predictor in confirming acute appendicitis diagnosis. Clinical and Applied Thrombosis/hemostasis 17(4): 362-366.

2. BalcikÖS, Bilen S, Ulusoy EK, Akdeniz D, Uysal S, et al. (2013) Thrombopoietin and mean platelet volume in patients with ischemic stroke. Clinical and Applied Thrombhemost 19(1): 92-95.

3. Danese S, Motte Cde L, Fiocchi C (2004) Platelets in inflammatory bowel disease: clinical, pathogenic, and therapeutic implications. American Journal of Gastroenterology 99(5): 938-945.
4. Öztürk ZA, Dag MS, Kuyumcu ME, Cam H, Yesil Y, et al. (2013) Could platelet indices be new biomarkers for inflammatory bowel diseases? European Review for Medical and Pharmacological Sciences 17(3): 334341.

5. Järemo P, Sandberg-Gertzen H (1996) Platelet density and size in inflammatory bowel disease. Thrombosis and Haemostasis 75(4): 560561.

6. Ranjith MP, Divya R, Mehta VK, Krishnan MG, KamalRaj R, et al. (2009) Significance of platelet volume indices and platelet count in ischaemic heart disease. Journal of Clinical Pathology 62(9): 830-833.

7. Camitta BM, Slye RJ (2012) Optimizing use of the complete blood count. PediatriaPolska 87(1): 72-77.

8. Schmid-Schönbein H, von Gosen J, Heinich L, Klose HJ, Volger E (1973) A counter-rotating «rheoscope chamber» for the study of the microrheology of blood cell aggregation by microscopic observation and microphotometry. Microvasc Res 6(3): 366-376.

9. Levin GY, Modin AP, Kudritsky SY, Sosnina LN (RF) Device for researching platelet aggregation / Pat. №2278381 RF, MPK G01N 33/48. №2005100408/14; applic. 11.01.05; publ.20.06.06, bul. №17, p. 6.

10. Bernhard H, Deutschmann A, Leschnik B, Schweintzger S, Novak M, et al. (2011) Thrombin generation in pediatric patients with Crohn's disease. Inflammatory Bowel Disease 17(11): 2333-2339.

11. Kamath S, Blann AD, Lip GY (2001) Platelet activation: assessment and quantification. European Heart Journal 22(17): 1561-1571.

12. Deutschmann A, Schlagenhauf A, Leschnik B, Hoffmann KM, Hauer A, et al. (2013) Increased procoagulant function of microparticles in pediatric inflammatory bowel disease: role in increased thrombin generation. Journal of Pediatric Gastroenterology and Nutrition 56(4): 401-407.

13. Preston RA, Jy W, Jimenez JJ, Mauro LM, Horstman LL, et al. (2003) Effects of severe hypertension on endothelial and plateletmicroparticlesHypertension 41(2): 211-217. (c) (i) This work is licensed under Creative

Submission Link: https://biomedres.us/submit-manuscript.php

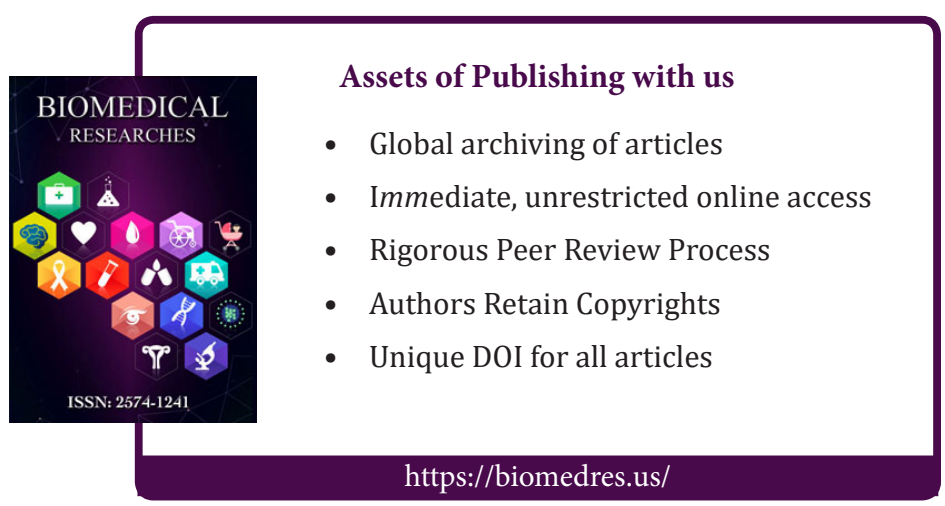

